\title{
Modificación de medicamentos en pacientes polimedicados y consecuencias de las mismas
}

\section{Sr. Editor:}

La prescripción de fármacos es el principal recurso utilizado en el Sistema Nacional de Salud para prevenir y tratar enfermedades ${ }^{1,2}$. Es importante que el médico realice este acto de forma adecuada y se cerciore del correcto cumplimiento de las indicaciones realizadas, para así obtener el máximo beneficio. El añadir, cambiar o modificar el tratamiento, ya sea por necesidad o con el fin de conseguir mayor eficiencia, puede llevar a confusiones importantes en los pacientes, especialmente en ancianos polimedicados. En los últimos años, dada la situación económica, nuestros pacientes se han visto sometidos a múltiples cambios, al menos en la forma física de sus medicamentos. Ello puede causar importantes confusiones, poniendo en peligro la seguridad del paciente, uno de los aspectos esenciales en cualquier organización sanitaria que quiere ofrecer una atención de calidad ${ }^{3,4}$.

Dada la trascendencia del tema, realizamos un estudio descriptivo transversal, con el fin de conocer qué porcentaje de pacientes sufrieron modificaciones en sus tratamientos en el último año, así como las consecuencias de las mismas. Para ello seleccionamos a 290 pacientes polimedicados (aquellos que toman cuatro o más fármacos) de los listados de cinco cupos de medicina de familia de nuestro centro de salud, a los que se les realizó una encuesta telefónica.

La muestra la formaban 176 mujeres y 114 hombres, con una edad media similar en ambos grupos. Al 48,9\% [IC95\% 43,2-54,7\%] se le realizó cambio por el mismo principio activo, mientras que el envase fue modificado en un 35,1\% [IC95\% 29,6-40,6]. Tan sólo un 7,9\% de los pacientes no sufrieron cambios en la medicación. Los cambios fueron realizados principalmente por el farmacéutico $(27,9 \%)$, seguido muy de cerca por el médico de atención primaria (22,0\%). Los cambios generaron dudas en el 54,8\% [IC95\% 49,1-60,5] de los encuestados, aumentando esas dudas con la edad de los pacientes. Ante estas confusiones la forma de resolución es diferente, como se aprecia en la figura 1.

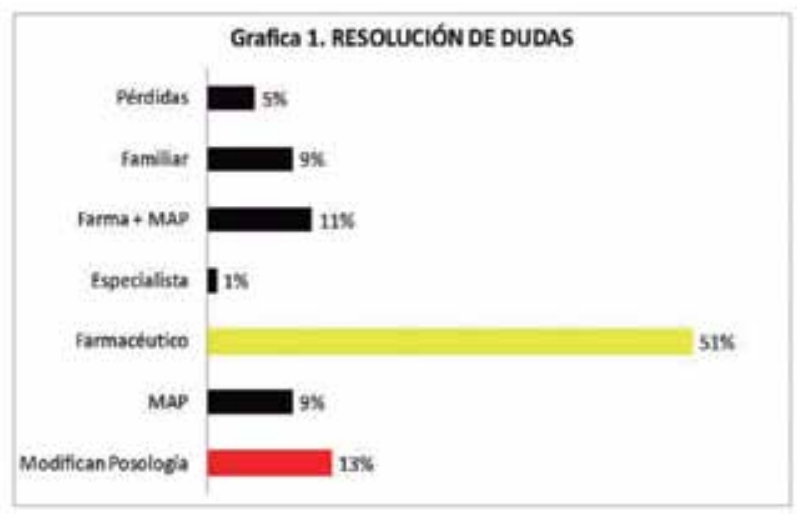

Los errores que se generan en la posología, aun siendo únicamente del 13,1\% [IC95\% 9,2-16,9], suponen un elevado riesgo en la seguridad del paciente, al tratarse de usuarios que en ocasiones manejan medicación cuyo mal cumplimiento puede conllevar eventos fatales.

Ya que las modificaciones han de realizarse inevitablemente, nosotros debemos identificar a los grupos más vulnerables, polimedicados ancianos y realizar en éstos una mayor actuación de educación sanitaria. Tanto los médicos de atención primaria como los farmacéuticos, a quienes más suelen recurrir los pacientes para resolver sus dudas, deben comprobar la comprensión de las instrucciones y asegurarse de que ha entendido el cambio, para conseguir un adecuado cumplimiento terapéutico y evitar eventos indeseables.

\section{BIBLIOGRAFÍA}

1. Task Force on Medicines Partnership. The National Collaborative Medicines Management Services Programme. Room for Review. Disponible en: http://www.npc.nhs.uk/ review medicines/intro/resources/room for review briefing. pdf [consultado 09/10/2013]

2. Polimedicación y prescripción inadecuada de fármacos en pacientes ancianos: ¿hacemos lo que podemos? Aten Primaria. 2006;38(9):476-82. 
3. Romero F. El RD 9/2011 sobre la prescripción por principio activo en la sanidad pública, aparte de limitar la libertad de prescripción genera dudas. Redacción Médica. Disponible en: http://www.smandaluz.com [consultado el 09/10/2013]

4. Ministerio de Sanidad y Consumo. Plan de calidad y del sistema nacional de salud. Traducción, validación y adaptación del cuestionario MOSPS para medir la cultura de seguridad del paciente en Atención Primaria. Disponible en: http://www.msssi.gob.es/organizacion/sns/planCalidadSNS/ docs/MOSPS.pdf [consultado el 09/10/2013]

Teresa Santamaría Rodríguez ${ }^{1}$

Carlos Gómez González ${ }^{2}$

${ }^{1}$ Médico de Familia. ${ }^{2}$ Residente de Medicina de Familia.

Centro de Salud Talavera-Centro (Talavera de la Reina) Correo electrónico: tsantamaria@sescam.jccm.es 